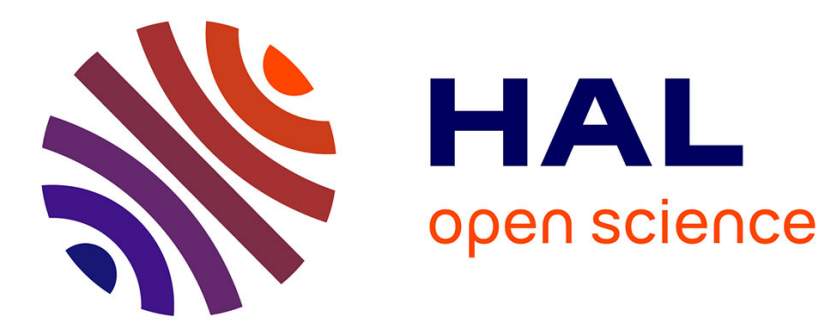

\title{
Synthesis of copper and zinc nanostructures by discharges in liquid nitrogen
}

H. Kabbara, J. Ghanbaja, C. Noël, T. Belmonte

\section{To cite this version:}

H. Kabbara, J. Ghanbaja, C. Noël, T. Belmonte. Synthesis of copper and zinc nanostructures by discharges in liquid nitrogen. Materials Chemistry and Physics, 2018, 207, pp.350-358. 10.1016/j.matchemphys.2017.12.087 . hal-02105358

\section{HAL Id: hal-02105358 \\ https://hal.univ-lorraine.fr/hal-02105358}

Submitted on 9 May 2019

HAL is a multi-disciplinary open access archive for the deposit and dissemination of scientific research documents, whether they are published or not. The documents may come from teaching and research institutions in France or abroad, or from public or private research centers.
L'archive ouverte pluridisciplinaire HAL, est destinée au dépôt et à la diffusion de documents scientifiques de niveau recherche, publiés ou non, émanant des établissements d'enseignement et de recherche français ou étrangers, des laboratoires publics ou privés. 


\title{
SYNTHESIS OF COPPER AND ZINC NANOSTRUCTURES BY DISCHARGES IN LIQUID NITROGEN
}

\author{
H. Kabbara ${ }^{1}$, J. Ghanbaja ${ }^{1}$, C. Noël ${ }^{2}$, T. Belmonte, ${ }^{2, *}$ \\ ${ }^{1}$ Université de Lorraine, Institut Jean Lamour, UMR CNRS 7198, NANCY, F-54011, France \\ ${ }^{2}$ CNRS, Institut Jean Lamour, UMR CNRS 7198, NANCY, F-54011, France
}

* corresponding author. Email: thierry.belmonte@univ-lorraine.fr

Keywords: arc discharges; nanostructures; alloys; oxidation 


\begin{abstract}
The peculiar behaviour of zinc depending on whether it is used pure or alloyed in $\mathrm{Cu}_{63} \mathrm{Zn}_{37}$ wire electrodes leads either to nanosheets or to nanoparticles when it is processed by nanosecond pulsed discharges in liquid nitrogen. Using one electrode of copper and one electrode of zinc gives core-shell $\mathrm{Cu} @ \mathrm{Zn}$ nanoparticles but no alloy for the smallest nanoparticles (typically below $20 \mathrm{~nm}$ ). Once nitrogen is evaporated, their oxidization in air produces $\mathrm{Cu}_{2} \mathrm{O} @ \mathrm{ZnO}$ nanoparticles. If both electrodes are made of $\mathrm{Cu}_{63} \mathrm{Zn}_{37}$, then the smallest nanoparticles are made of $\mathrm{Cu}$ and $\mathrm{Zn}$ and oxidized next in air to give $\mathrm{Cu}_{2} \mathrm{O}$ and $\mathrm{ZnO}$ nanoparticles. No alloy is formed either. Time-resolved optical emission spectroscopy gives clues on the origin of such behaviours, explaining why no alloy is formed when electrodes are made of different materials.
\end{abstract}




\section{INTRODUCTION}

Low cost flexible and printed electronics requires conductive layers with high electrical conductivity [1]. In particular, these layers are fabricated by printing of metal nanoparticles conductive inks [2]. Currently most conductive inks widely used are based on silver nanoparticles [3]. Copper is also possible but suffers from air oxidation [4].

Recently, Panuthai et al. [5] proposed to use copper-zinc nanoparticles (hereinafter denoted NPs). They resorted to submerged arc discharges as synthesis process. Spherical nanoparticles were synthesized from $90 \mathrm{Cu} / 10 \mathrm{Zn}$ and $65 \mathrm{Cu} / 35 \mathrm{Zn}$ alloy electrodes in three different dielectric liquids (ethylene glycol, ethanol and deionized water). The size distribution of the nanoparticles are slightly liquid-dependent. The smallest (resp. the largest) nanoparticles, from 5 to $15 \mathrm{~nm}$ (resp. from 20 to $50 \mathrm{~nm}$ ) were obtained in ethylene glycol (resp. water). These particles contained $\mathrm{Cu}, \mathrm{Cu}-\mathrm{Zn}$, and zinc oxide without copper oxide.

Holse et al. [6] studied the dynamic behavior of $\mathrm{CuZn}$ nanoparticles under oxidizing and reducing conditions. Upon oxidation in $\mathrm{O}_{2}$, metal clusters produced from a cluster source transform into a polycrystalline cluster consisting of separate $\mathrm{CuO}$ and $\mathrm{ZnO}$ nanocrystals. Specifically, the $\mathrm{CuO}$ is observed to segregate to the cluster surface and partially cover the $\mathrm{ZnO}$ nanocrystals.

The apparent discrepancy between both previous studies motivated the present work. Several attempts to synthesize alloy NPs by discharges in liquids were recently reported. For instance, Pootawang et al. [7] used DC pulsed discharges between Pt and Ag electrodes in a solution containing water, $\mathrm{NaCl}$ and sodium dodecylsulfonate. They obtained bimetallic particles $\mathrm{Ag} / \mathrm{Pt}$ in the form of nanocomposites and Pt oxide NPs. Kim et al. [8] employed Pt and Pd electrodes immersed in deionized water containing $\mathrm{KOH}$. Under continuous DC excitation, $\mathrm{Pt}_{1} \mathrm{Pd}_{99}$ or $\mathrm{Pt}_{94} \mathrm{Pd}_{6}$ NPs were obtained whereas with bipolar pulses, a mixture containing $\mathrm{Pt}, \mathrm{Pd}$ and $\mathrm{Pt}_{40} \mathrm{Pd}_{60}$ ( 2-3 $\mathrm{nm}$ in diameter) alloy NPs was produced. Saito et al. [9] studied many systems: $\mathrm{NiCu}, \mathrm{NiCr}, \mathrm{SnPb}, \mathrm{SbSn}$ and $\mathrm{NiSn}$. A cathode of one of these alloys and an anode of 
Pt were immersed in a $0.1 \mathrm{M}(\mathrm{NaOH}$ or $\mathrm{KCl})$ electrolyte and submitted to direct $\mathrm{DC}$ excitation. First, NPs made of solid solution of $\mathrm{Cu}-43 \% \mathrm{Ni}, \mathrm{Cu}-66 \% \mathrm{Ni}, \mathrm{Ni}-21 \% \mathrm{Cr}$ and $\mathrm{Ni}-$ 9\% Cr were obtained. Next, alloys NPs of $\mathrm{Bi}-30 \% \mathrm{Sn}, \mathrm{Sn}-25 \% \mathrm{Zn}$, and $\mathrm{SnSb}$ were found to be oxidized. Finally, NPs made from $\mathrm{Sn}-35 \% \mathrm{~Pb}$ eutectic showed the coexistence of $\mathrm{Pb}$-rich and Sn-rich phases. In all cases, very large NPs were obtained, exhibiting diameters beyond 100 nm typically. Mardanian et al. [10] started from a powder of $\mathrm{CuInSe}_{2}$ placed in a cup filled with ethanol and used a tungsten wire as anode. Under a pulsed AC excitation, they could obtain a mixture of $\mathrm{Se}, \mathrm{In}, \mathrm{In}_{4} \mathrm{Se}_{3}, \mathrm{CuSe}_{2}$ and $\mathrm{CuInSe}_{2}$ NPs. Large amount of primary nanoparticles ranging from 20 to $40 \mathrm{~nm}$ in size were aggregated to form spherical clusters of about 80-200 nm in diameter. From Co and Ag electrodes immersed in a $0.1 \mathrm{M}(\mathrm{HCl}$ and $\mathrm{NaOH}$ ) electrolyte, Chang et al. [11] combined a DC pulsed excitation with ultrasonic vibration (at $\sim 20 \mathrm{kHz}$ ). They got a mixture of $\mathrm{Ag}, \mathrm{Co}$ and $\mathrm{Co}_{3} \mathrm{O}_{4}$ NPs with an average size of $30 \mathrm{~nm}$.

Oxidation of as-produced NPs occurs either directly in the liquid or in air, once the NPs are removed from the liquid to be transferred into a TEM chamber for instance. In any situation, we readily understand that this oxidation has:

- No influence if NPs are made of noble metals like Pt or Pd,

- A weak influence if the nanoparticle size is large (beyond $20 \mathrm{~nm}$ typically). Then, for a so-called "valve" metal, the passive oxide layer protects the core of the nanoparticle, but does not contribute to increasing the oxygen content that remains negligible with respect to the NP volume.

- A strong influence if the NPs radius is of the order of the thickness of the passive oxide layer, i.e. 3-5 nm for aluminum for instance, or if the NP is large but made of a non-valve metal such as iron. Then, oxidation of the particle is time-dependent so that after a sufficiently long time, the metallic particle is fully converted into oxide.

We chose to investigate the $\mathrm{Cu}-\mathrm{Zn}$ system, more documented thanks to the work by Holse $e t$ 
al. [6]. By studying the erosion of brass electrodes in liquid nitrogen, we were able to determine whether alloy NPs were formed or not before air oxidation as described hereinafter. Complementary experiments were performed with one zinc electrode and one copper counterelectrode in order to check whether it was possible or not to create $\mathrm{CuZn}$ alloy nanostructures by this method. A special attention will be paid to time-resolved optical emission spectroscopy to help us to support our reasoning.

\section{EXPERIMENTAL SET-UP}

The experimental set-up was presented in detail in reference [12]. Briefly, a pin-to-pin electrode configuration was used. Electrodes were single-phase $\alpha$ brass alloy wires ( $1 \mathrm{~mm}$ in diameter; 63 wt.\% $\mathrm{Cu}-37$ wt.\% Zn solid solution). The $\alpha$-brass alloy melts at $\sim 873 \mathrm{~K}$ $\left(600^{\circ} \mathrm{C}\right)$. A high DC voltage power supply (Technix SR15-R-1200-15 kV-80 mA) fed a solid-state switch (Behlke HTS-301-03-GSM) connected to one pin-electrode, the other electrode being grounded. The voltage rise time was $20 \mathrm{~ns}$ without ballast resistor.

Experiments were run in liquid nitrogen, which is known to be inert in our conditions. The experimental conditions retained here are an applied voltage of $+10 \mathrm{kV}$ and an inter-electrode gap distance of $100 \mu \mathrm{m}$. The discharge pulse is $75 \mathrm{~ns}$ long.

For core-shell (expected to be alloy@Zn) structures, the process is two-step. After the dielectric liquid is enriched with nanoparticles produced by the erosion of $\mathrm{CuZn}$ electrodes (i.e. after about $30 \mathrm{~min}$ of successive discharges ignited at $10 \mathrm{~Hz}$ ), the $\mathrm{CuZn}$ electrodes are removed and replaced by Zinc electrodes. Then, another set of discharges is run for 30 minutes at $10 \mathrm{~Hz}$ in this new configuration.

Nanoparticles are collected by sedimentation on a silicon wafer located under the pinelectrodes. We resorted to scanning electron microscopy (SEM) - XL30S-FEG by Philips for structural and chemical observations. The XL30S-FEG microscope was equipped with an EDXS (Energy-Dispersive X-ray Spectrometer) used for elemental analysis and a TLD detector (through the lens detector) used for high resolution imaging. A Philips CM200 device 
and a JEOL ARM 200F Cold FEG device were used for TEM investigation in order to study the crystallinity and the chemical composition of NPs.

Optical emission spectroscopy was performed with a $550 \mathrm{~mm}$ focal length monochromator (Jobin-Yvon TRIAX 550) equipped with a $100 \mathrm{~g} \mathrm{~mm}^{-1}$ grating for overall spectra in the (250-900 nm) visible range, lines being strongly broadened and high spectral resolution useless. It was coupled with a HORIBA Jobin-Yvon i-Spectrum Two iCCD detector. Each measurement is averaged over 50 spectra recorded with an exposure time of $50 \mathrm{~ns}$.

Although discharges in dielectric liquids are known to be stochastic, using a solid-state switch with a 20-ns rise time ensures a high level of reproducibility because breakdown necessarily occurs within a time window inferior to the exposure time (see reference [13] for further details).

\section{RESULTS AND DISCUSSION}

\subsection{Erosion of pure metals}

If eroding copper electrodes under the chosen conditions leads to the synthesis of NPs with spherical shapes (Fig. 1a), eroding zinc electrodes gives mainly 2-dimensional nanostructures (nanosheets) with few spread NPs (Fig. 1b). Spherical NPs are made of CuO, since copper NPs are exposed to air before TEM analysis, once liquid nitrogen has fully evaporated. These primary NPs have sizes ranging typically between 2 and $10 \mathrm{~nm}$. However, larger primary NPs, with diameters closer to $30-50 \mathrm{~nm}$ are also present, but to a lesser extent. Similarly, nanosheets are made of $\mathrm{ZnO}$. Typically, their thickness is about $4 \mathrm{~nm}$, according to unreported AFM measurements. Unreported diffraction patterns and micro-EDX analyses (available on demand) prove undoubtedly that both metals are oxidized as $\mathrm{CuO}$ and $\mathrm{ZnO}$ respectively.

The behaviour of zinc is uncommon for a metal eroded by spark discharges in liquids. We assume that the synthesis of zinc nanosheets proceeds by a kind of exfoliation mechanism where a few atomic layers are detached from zinc grains submitted to the plasma flux. 
However, till now, no clear explanation dealing with the synthesis mechanism of these nanosheets can be put forward.

\subsection{Observation after air oxidation of NPs from alloy electrodes}

Erosion of $\mathrm{Cu}_{63} \mathrm{Zn}_{37}$ wires leads to the synthesis of spherical NPs, as shown in Fig. 2. These NPs are agglomerated on the TEM grid, as shown in Fig. 2a. The corresponding Selected Area Electron Diffraction Pattern shows the presence of $\mathrm{Cu}_{2} \mathrm{O}$ and $\mathrm{ZnO}$ (Fig. 2b). Both types of NPs are crystallized as visible on High-Resolution TEM images (Fig. 2c). The size distribution of primary NPs extends typically between 2 and $8 \mathrm{~nm}$ for $\mathrm{Cu}_{2} \mathrm{O}$ and $\mathrm{ZnO}$. Larger primary NPs, with diameters closer to $30-50 \mathrm{~nm}$ are also present, but to a lesser extent.

We cannot put forward any irrevocable mechanism to explain why spherical nanoparticles of zinc are produced when alloy electrodes are used whereas sheets are formed with pure zinc. The exfoliation mechanism mentioned hereinabove is useful to intuitively understand how the change of material might affect the shape of the synthesized nano-objects. However, convincing proofs are still lacking to support this approach.

To confirm the chemical composition of NPs, Electron Energy Loss Spectroscopy was used. Recorded spectra were compared with reference spectra taken from references [14] and [15]. In Fig. 3a, the EEL spectrum of the synthesized sample matches undoubtedly the $\mathrm{ZnO}$ reference spectrum. It is also clear in Fig. 3b where copper oxide NPs obtained in the present conditions are made of $\mathrm{Cu}_{2} \mathrm{O}$.

Fig. 4 shows an EDS mapping of an agglomerate of NPs. Both phases are homogeneously distributed, which suggests that both elements are emitted simultaneously from the alloy electrodes, and not successively.

The fact that NPs are made of $\mathrm{Cu}_{2} \mathrm{O}$ instead of $\mathrm{CuO}$ indicates that the presence of zinc hinders full oxidation of copper. At this stage, two assumptions can be made: Either alloy NPs are formed and $\mathrm{Cu}$ and $\mathrm{Zn}$ move apart due to air oxidation, as shown in the work by Holse et al. [6] or $\mathrm{Cu}$ and $\mathrm{Zn}$ NPs are created in the liquid and zinc acts as a Getter to limit copper 
oxidation in air. To resolve this issue, we benefit from the possibility to synthesize zinc sheets in order to coat NPs made from brass electrodes and produce core-shell structures. The result of this experiment is given in Fig. 5 for a small-size ( 18 nm in diameter) NP. Core-shell nanoparticles were actually made. Zinc sheets wrap copper nanoparticles produced during the first step of the process. Once liquid nitrogen is totally evaporated, zinc gets oxidized and $\mathrm{Cu} @ \mathrm{ZnO}$ core-shell structures are obtained. Zn@ZnO NPs were probably synthesized too but they could not be identified as such. In Fig. 6, EDX spectra recorded on a medium-size $(\sim 115$ $\mathrm{nm}$ in diameter) core-shell NP confirm that a $\mathrm{Cu} @ \mathrm{ZnO}$ nanostructure was formed. Traces of oxygen $(0.47$ wt.\%) are likely due to the zinc oxide shell. Zinc $(2.08$ wt.\%) can be partly or totally present in the shell if it is not fully oxidized. However, we cannot exclude the possibility that copper contains also a small fraction of zinc. To conclude, we can claim after analysis of a large number of small and medium-size nanoparticles that erosion products of brass electrodes contain a negligible, if not null (below 2-3 wt.\% typically), fraction of the element that is not dominant (i.e. copper for zinc NPs and zinc for copper NPs).

\subsection{Observation after air oxidation of NPs from one zinc electrode and one copper electrode}

From the previous results, we infer that zinc and copper are emitted simultaneously from the electrodes but their reaction in the gas phase is limited. To check this assumption, we used pure zinc (grounded) and pure copper $(+10 \mathrm{kV})$ electrodes, mounted opposite one another. In this situation, zinc sheets and copper nanoparticles are produced by erosion of the zinc and copper electrodes respectively, in accordance with results obtained when both electrodes are made of the same metal, either copper or zinc. Agglomerates appear as a network of zinc sheets mixed with copper oxide nanoparticles (Fig. 7a). In fact, copper NPs are imperfectly wrapped in $\mathrm{ZnO}$ shell (Fig. 7b). In Fig. 7c, the EELS spectrum indicates that $\mathrm{Cu@Zn} \mathrm{core-}$ shell nanostructures produced in liquid nitrogen are $\mathrm{Cu}_{2} \mathrm{O} @ \mathrm{ZnO}$ after air exposure. Here again, zinc and copper do not react together to produce an alloy. 


\subsection{Time-resolved optical emission spectroscopy}

In Fig. 8, are identified the main transitions observed during discharges in liquid nitrogen when both electrodes are made of zinc, copper or brass. These transitions are reported in the Grotrian diagrams provided as supplemental material 1. We distinguish three main groups: copper lines around $515 \mathrm{~nm}$, zinc lines around $470 \mathrm{~nm}$, and UV (copper as well as zinc) lines around $330 \mathrm{~nm}$. The two former groups are due to transitions with similar energies. The latter group is due to more energetic transitions, two of which being resonant in the case of copper (lines at 324.75 and $327.40 \mathrm{~nm}$ ). Time-resolved data are provided in Fig. 9 for $\mathrm{Cu}_{63} \mathrm{Zn}_{37}$ electrodes and for the $\mathrm{Cu}(+10 \mathrm{kV})-\mathrm{Zn}$ (grounded) configuration A broad continuous emission is observed at short times (before $250 \mathrm{~ns}$ typically), which is essentially due to electron-ion recombination [13]. Then, optical transitions start popping up in the spectrum when the medium becomes optically thinner.

We also notice that UV copper lines are self-absorbed. In Fig. 10, high-resolution spectra recorded specifically at the wavelengths of resonant transition do show negative peaks. As already discussed in the case of aluminium electrodes [13], self-absorption is due to the "shell-like" structure of the plasma where layers of species with varying density enable the trapping of photons emitted at the centre of a given resonant line. No resonant transition of zinc (self-absorbed or not) was visible in the present conditions. Indeed, three resonant transitions $\left(4 \mathrm{~s} 4 \mathrm{p}{ }^{3} \mathrm{P}_{1,2,3}^{\circ} \rightarrow 4 \mathrm{~s}^{2}{ }^{1} \mathrm{~S}\right)$ could be observed around $307 \mathrm{~nm}$, but these transitions originate from metastable states and the corresponding de-excitation probabilities are 4 orders of magnitude lower than those of copper $\left(\sim 3.3 \times 10^{4} \mathrm{vs} \sim 1.4 \times 10^{8} \mathrm{~s}^{-1}\right)$.

In Fig. 11, the time evolution of selected lines (one per group identified previously) is depicted. Time-resolved spectra are provided as additional information (see supplemental material 2). When electrodes are made of $\alpha-\mathrm{Cu}_{63} \mathrm{Zn}_{37}$ brass (Fig. 11a), copper and zinc are expected to be produced simultaneously, the electrode melting at $600^{\circ} \mathrm{C}$ and emitting both elements at the same time. The emissions of zinc and copper lines at 481.05 and $515.32 \mathrm{~nm}$ 
respectively, i.e. with comparable energies, start simultaneously (within the accuracy of our measurement which is $\pm 25 \mathrm{~ns}$.). However, this does not prove that both vapours are produced simultaneously. Indeed, the selected UV resonant transition of copper at $324.75 \mathrm{~nm}$ can be observed $150 \mathrm{~ns}$ sooner. This feature is important for it shows that the emission of a given transition cannot be straightforwardly associated with the production of the metallic vapour from one electrode. Indeed, the $\mathrm{Cu}$ transition at $324.75 \mathrm{~nm}$ starts being visible after $100 \mathrm{~ns}$ only, which proves the presence of copper in the early stages of the discharge process. However, copper lines around $515 \mathrm{~nm}$ are visible only $150 \mathrm{~ns}$ latter.

Besides, it turns out that other UV transitions between 328 and $334 \mathrm{~nm}\left(4 \mathrm{~s} 4 \mathrm{~d}^{3} \mathrm{D}_{1,2,3} \rightarrow 4 \mathrm{~s} 4 \mathrm{p}\right.$ ${ }^{3} \mathrm{P}_{1,2,3}^{\circ}$ are also observed but only after $250 \mathrm{~ns}$. As the upper levels of these transitions are high-energy states (all around $7.78 \mathrm{eV}$ ), we think that a sufficiently long period of time is required to populate them. Intensity being proportional to concentration, these transitions can pop out of the spectrum only when the upper level is sufficiently populated. Because the timescale over which the discharge occurs is very short (much shorter than the $\sim 3 \mu$ s needed typically in these conditions to reach local thermodynamic equilibrium), we can observe a gradual populating of the excited states, leading to a discrepancy in the order of appearance of lines according to their transition energy.

The simultaneous emission of zinc and copper lines at 481.05 and $515.32 \mathrm{~nm}$, even though it does not prove that both elements from the electrodes are emitted together, likely results from such a concomitance. The upper levels of both transitions are near, lying at 6.19 and $6.65 \mathrm{eV}$ for copper and zinc respectively. Brass erosion, if the two elements are emitted simultaneously, should lead to a ratio of $\sim 1.7$ (i.e. 63/37) only between the concentrations of elements. Then, the upper levels of lines at 481.05 and $515.32 \mathrm{~nm}$ should be populated alike, leading to simultaneous emissions.

In the case of the $\mathrm{Cu}-\mathrm{Zn}$ arrangement, zinc is expected to melt a bit before brass does and copper much after $\left(\mathrm{Cu}\right.$ melts at $\left.\sim 1085^{\circ} \mathrm{C}\right)$. Contrary to the former situation, there is a delay of 
$100 \mathrm{~ns}$ in the emission of copper lines around $515 \mathrm{~ns}$ with respect to zinc lines around $480 \mathrm{~ns}$. The self-absorbed lines of copper are not observed in these conditions. The emission of copper is differed in this arrangement because the melting of the electrode occurs at much higher temperature. For the same reason, the concentration of copper is probably much weaker than with brass electrodes, which is confirmed by the very weak intensity of the copper line at $511.20 \mathrm{~nm}$ (see supplemental material 3). Then, it is very interesting to see that the zinc UV emission at $334.50 \mathrm{~nm}$ appears after the emission of the zinc line at 481.05 $\mathrm{nm}$ and before the copper line at $511.20 \mathrm{~nm}$. As previously, this behaviour is attributed to the time required to sufficiently populate the upper levels of these transitions that lie at high energy.

From these results, a pretty clear picture of emission processes can be drawn. In the case of brass electrodes, both elements are certainly emitted simultaneously, quite early in the discharge because of the low melting point of the alloy. The plasma is highly concentrated in zinc and copper and self-absorption is observed for resonant lines of copper but not of zinc where the emissive states are metastable. Then, energy levels are progressively populated, leading to new emissions. In the case of $\mathrm{Zn}$ and $\mathrm{Cu}$ electrodes, the zinc vapour is emitted first. Copper emission is delayed because of the high melting point of the metal that limits also the concentration of the metal in the discharge. We can expect that light emission is not homogenously distributed over the discharge length, zinc (respectively copper) emission being probably mainly localized near the zinc (respectively copper) electrode. Consequently, optical emission spectroscopy explains clearly why alloy nanoparticles cannot be synthesized in this situation. For brass electrodes, it is not so clear. Both elements are emitted simultaneously, probably distributed homogeneously in the discharge, but they do not form alloy nanoparticles, even though nanoparticles can be doped up to 1 or $2 \%$ by the other element. The origin of this behaviour is still not understood but it might be due to the intensity 
of our discharges which is about 10 times higher than Panuthai's (50 to $100 \mathrm{~A}$ vs $5 \mathrm{~A}$ ). Elements of the alloy could perharps be more efficiently split in our case.

\subsection{Discussion}

In the work of Panuthai et al. [5], alloy NPs synthesized from $65 \mathrm{Cu} / 35 \mathrm{Zn}$ and $90 \mathrm{Cu} / 10 \mathrm{Zn}$ wires in ethylene glycol, ethanol and deionized water are characterized either without reduction or with successive reduction by L-ascorbic acid. These alloy NPs $(5-10 \mathrm{~nm}$ in diameter) exhibit in all experimental conditions similar compositions to the wires used, atoms of copper and zinc being uniformly distributed over the whole cluster or particles. If we assume with the authors that zinc oxide NPs are reduced by L-ascorbic acid, then it is very difficult to admit that this does not hold as well for CuZn NPs that should be oxidized by either liquid. Indeed, as shown in the work by Holse et al. [6], CuZn NPs must be elaborated under UHV to avoid their oxidation. One way to explain the results by Panuthai et al. [5] is then to assume that small CuZn NPs are functionalized by specific chemical groups like $\mathrm{OH}$ for all liquids or $\mathrm{CO}$ for ethanol and ethylene glycol. Indeed, hydroxyl groups for instance are known to passivate some NPs like silicon for instance [17] by grafting $\mathrm{OH}$ functional groups onto NPs surface. Grafting of $\mathrm{OH}$ or $\mathrm{CO}$ groups would affect copper or copper alloy but not zinc. Indeed, copper NPs are found to remain metallic, whereas zinc NPs are easily transformed into $\mathrm{ZnO}$. In $\mathrm{Cu}_{63} \mathrm{Zn}_{37}$ and $\mathrm{Cu}_{90} \mathrm{Zn}_{10}$ brass alloys, this would be true as well, the oxidation of zinc being hindered in this case by the presence of copper.

Recent works [18-19] also showed that elastic strain can tune the catalytic activity in a controlled manner. For instance, the change of the d-band by either compression (e.g. Ni and $\mathrm{Pt}$ ) or by tension (e.g. $\mathrm{Cu}$ ) improves the catalycity in the case of the hydrogen evolution reaction. Reciprocally, the strain effect must play a crucial role in the formation of alloy, by minimizing the energy required to stabilize the alloy. Thermal gradients being huge in our conditions (directed from the hot plasma region to the cold liquid), they might favor the 
development of strain within particles in a way that it is not compatible with the stabilization of alloys.

\section{CONCLUSION}

We showed that nanosecond pulsed discharges in liquid nitrogen between $\mathrm{Cu}_{63} \mathrm{Zn}_{37}$ wire electrodes lead to the synthesis of $\mathrm{Cu}$ and $\mathrm{Zn}$ spherical nanoparticles, which get oxidized in the air once nitrogen is evaporated and form $\mathrm{Cu}_{2} \mathrm{O}$ and $\mathrm{ZnO}$. When both electrodes are made of a different metal, i.e. zinc and copper, core-shell $\mathrm{Cu}_{2} \mathrm{O} @ \mathrm{ZnO}$ NPs are obtained after air exposure. 2D zinc sheets are formed when a pure zinc electrode is used whereas spherical zinc NPs are formed when the electrodes are made of $\mathrm{Cu}_{63} \mathrm{Zn}_{37}$.

In the case of $\mathrm{Zn}$ and $\mathrm{Cu}$ electrodes, optical emission spectroscopy shows that copper and zinc vapours are not emitted by the electrodes neither simultaneously nor homogeneously in the interelectrode gap. Consequently, alloy nanoparticles cannot be synthesized in this situation. For brass electrodes, even though both elements are emitted simultaneously and probably distributed homogeneously in the discharge, they do not form any alloy nanoparticles either. Copper and zinc are then split when emitted and do not get alloyed during the discharge process, maybe because of the short duration of the discharge.

The possibility to form alloy nanoparticles by discharges in liquids was showed by Panuthai et al. [5]. The oxidation of these nanoparticles, even with diameters as small as $10 \mathrm{~nm}$, seems to be hindered, probably by surface functionalization. This might explain why the oxidation mechanism described by Holse et al. [6], where alloy NPs get split by oxidation into $\mathrm{CuO}$ and $\mathrm{ZnO}$, does not hold in these conditions.

From these results, it is now important to understand how Panuthai et al. could get alloy NPs instead of $\mathrm{Cu}$ and $\mathrm{Zn} \mathrm{NPs.} \mathrm{Understanding} \mathrm{why} \mathrm{no} \mathrm{oxidation} \mathrm{occurs} \mathrm{in} \mathrm{their} \mathrm{conditions} \mathrm{will}$ also be a key point to control the synthesis of alloy NPs by discharges in liquids. 


\section{REFERENCES}

[1] Y. Chen, J. Au, P. Kazlas, A. Ritenour, H. Gates, M. McCreary, Nature 423 (2003) 136

[2] Y.-L. Tai, Z.-G. Yang, Surf. Interface Anal. 44 (2012) 529-534

[3] A. Kamyshny, J. Steinke, S. Magdassi, Open Appl. Phys. J. 4 (2011) 19-36

[4] X.-F. Tang, Z.-G. Yang, W.-J. Wang, Colloids Surf. 360 (2010) 99-104

[5] N. Panuthai, R. Savanglaa, P. Praserthdam, S. Kheawhom, Jap. J. Appl. Phys. 53 (2014) 05HA11

[6] C. Holse, C. F. Elkjær, A. Nierhoff, J. Sehested, I. Chorkendorff, S. Helveg, J. H. Nielsen, J. Phys. Chem. C 119 (2015) 2804-2812

[7] P. Pootawang, N. Saito, O. Takai, S.-Y. Lee, Nanotechnol. 23 (2012) 395602

[8] S.-M. Kim, Y.-J. Lee, J.-W. Kim, S.-Y. Lee, Thin Solid Films 572 (2014) 260-265

[9] G. Saito, Y. Nakasugi, T. Yamashita, T. Akiyama, Nanotechnol. 25 (2014) 135603

[10] M. Mardanian, A. A. Nevar, M. Nedel'ko, N. V. Tarasenko, Eur. Phys. J. D 67 (2013) 208

[11] H. Chang, M.-J. Kao, C.-S. Jwo, C.-G. Kuo, Y.-H. Yeh, W.-C. Tzeng, J. Alloys Comp. 504S (2010) S376-S379

[12] A. Hamdan, C. Noel, F. Kosior, G. Henrion, T. Belmonte, J. Appl. Phys. 113 (2013) 043301

[13] A. Hamdan, C. Noël, J. Ghanbaja, T. Belmonte, Plasma Chem. Plasma Process. 34 (2014) 1101-1114

[14] F. Hofer, P. Golob, Ultramicroscopy 21 (1987) 379-384

[15] R. D. Leapman, L. A. Grunes, P. L. Fejes, Phys. Rev. B. 26 (1982) 614-635

[16] A. Kramida, Yu. Ralchenko, J. Reader, NIST ASD Team (2016). NIST Atomic Spectra Database (version 5.4), [Online]. Available: http://physics.nist.gov/asd [Sun Nov 13 2016]. National Institute of Standards and Technology, Gaithersburg, MD. 
[17] S. Mitra, V. Švrček, D. Mariotti, T. Velusamy, K. Matsubara, M. Kondo. Plasma Process. Polym. 11 (2014) 158-163

[18] K. Yan, S. Ki Kim, A. Khorshidi, P. R. Guduru, A. A. Peterson, J. Phys. Chem. C 121 (2017) 6177-6183

[19] K. Yan, T. A. Maark, A. Khorshidi, V. A. Sethuraman, A. A. Peterson, P. R. Guduru, Angewandte Chemie International Edition 55 (2016) 6175-6181 

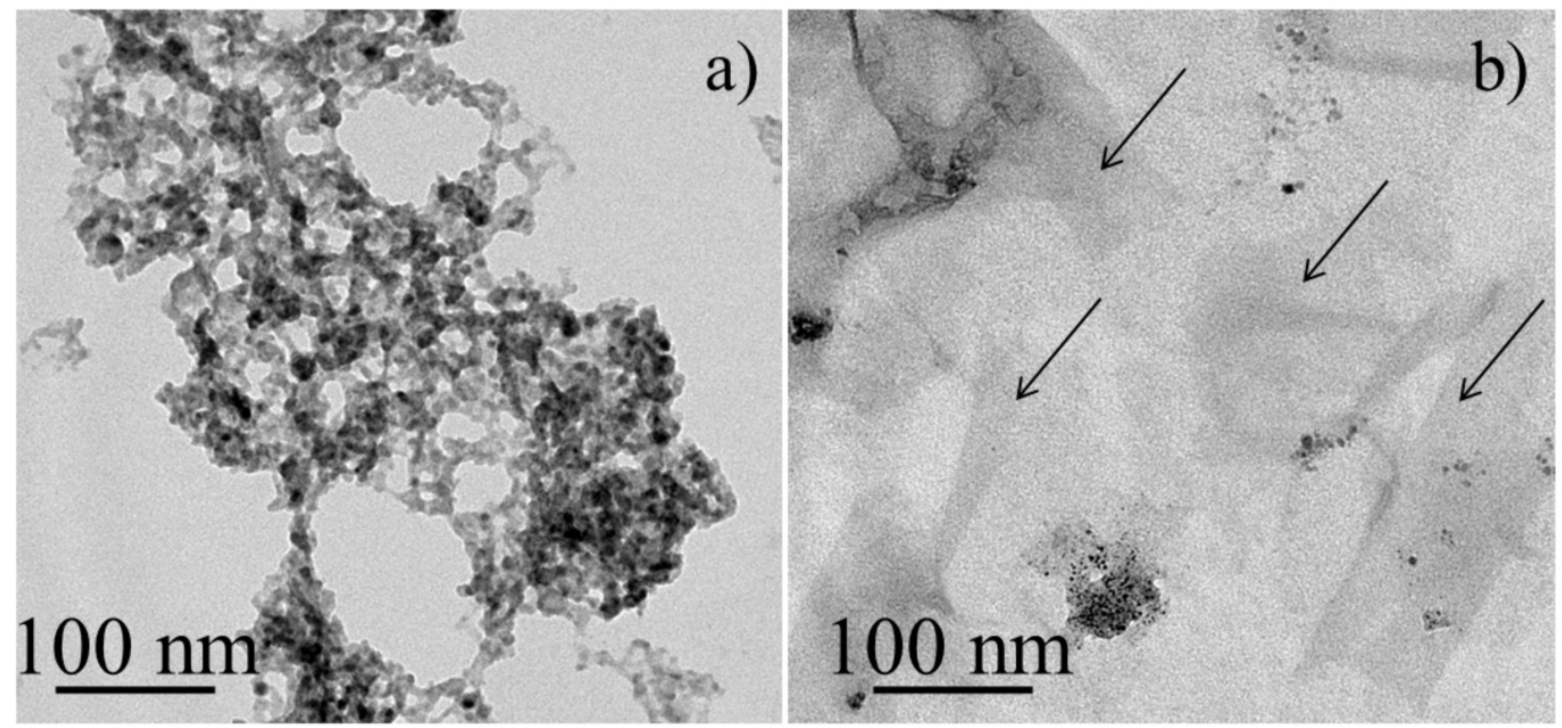

Figure 1: a) Copper oxide $(\mathrm{CuO})$ nanoparticles synthesized between two $\mathrm{Cu}$ electrodes immerged in liquid nitrogen and observed after air exposure by TEM. b) Zinc oxide (ZnO) sheets (depicted by arrows) and nanoparticles synthesized between two $\mathrm{Zn}$ electrodes immerged in liquid nitrogen and observed after air exposure by TEM. 

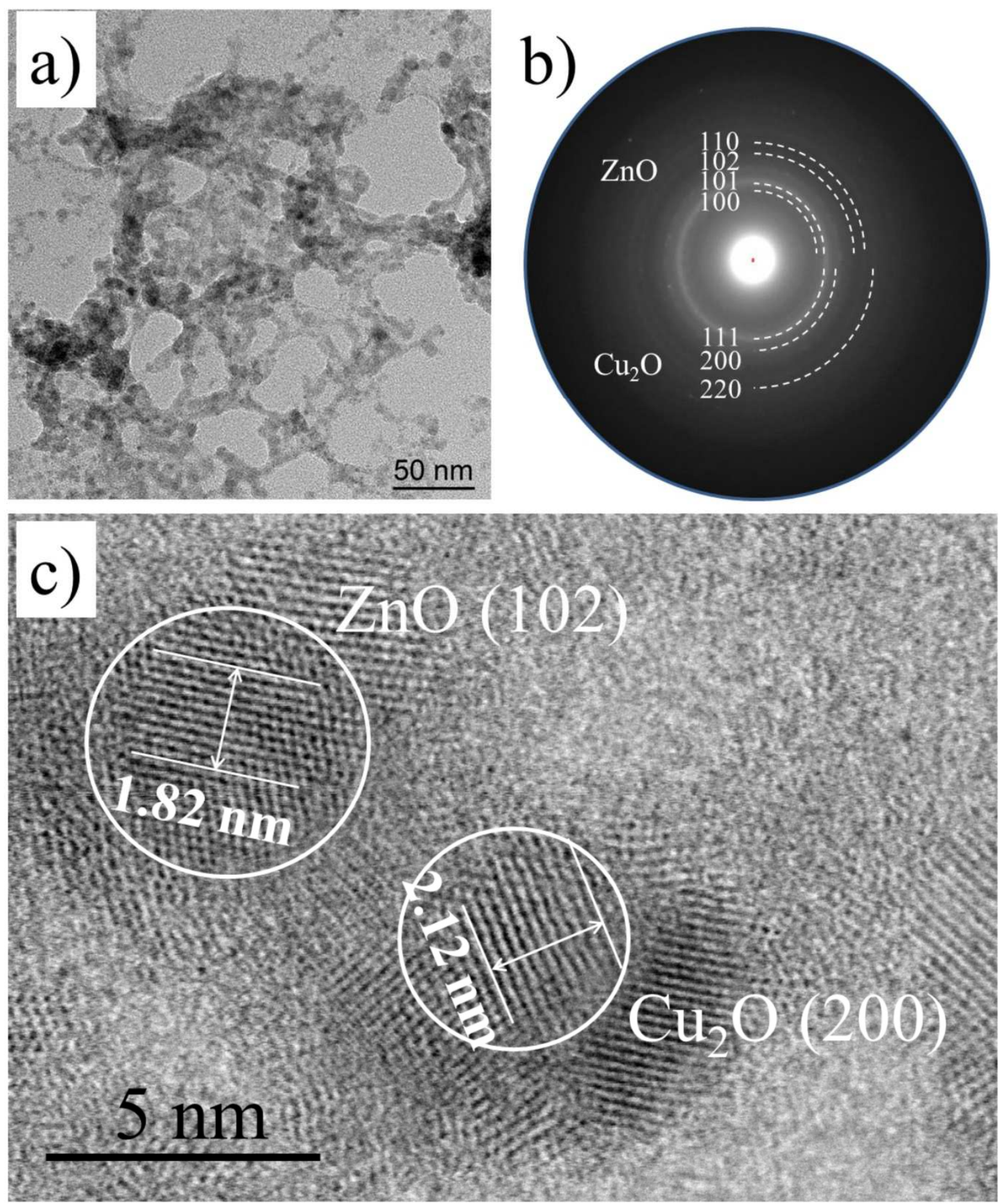

Figure 2: a) Low magnification bright field TEM images of NPs synthesized with brass electrodes. b) Corresponding Selected Area Electron Diffraction pattern showing the simultaneous presence of $\mathrm{Cu}_{2} \mathrm{O}$ and $\mathrm{ZnO}$. c) High resolution TEM images showing crystalline $\mathrm{ZnO}$ and $\mathrm{Cu}_{2} \mathrm{O}$ NPs. The interplanar distance is measured from 10 consecutive planes, as depicted by arrows. 

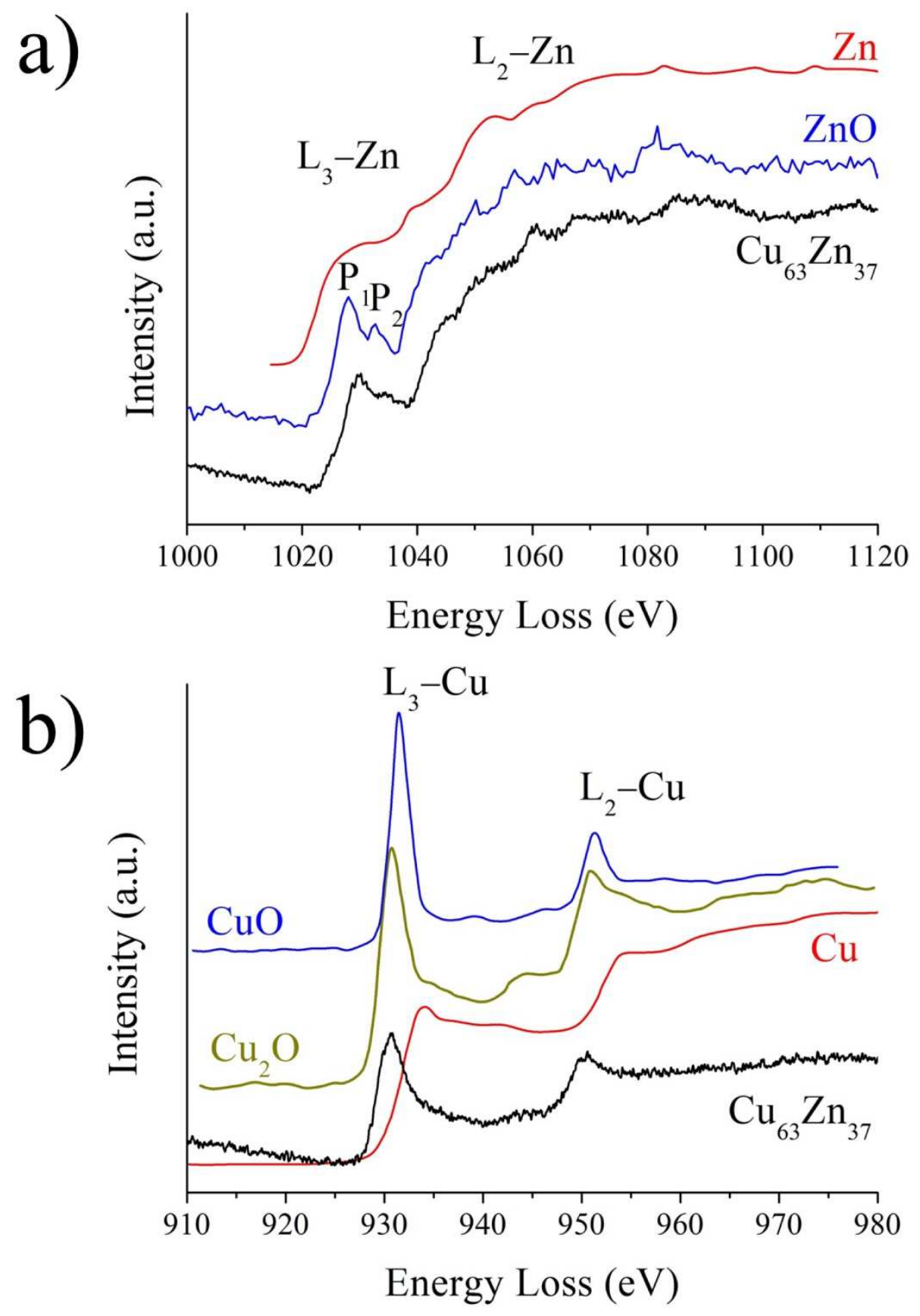

Figure 3: a) Electron Energy Loss spectrum corresponding to the $\mathrm{Zn}-\mathrm{L}$ edge. The spectrum labelled $\mathrm{Cu}_{63} \mathrm{Zn}_{37}$ corresponding to the present experimental conditions matches the $\mathrm{ZnO}$ reference spectrum. $\mathrm{Zn}$ and $\mathrm{ZnO}$ reference spectra are taken from [14]. b) Electron Energy Loss spectrum corresponding to the $\mathrm{Cu}-\mathrm{L}$ edge. The spectrum labelled $\mathrm{Cu}_{63} \mathrm{Zn}_{37}$ corresponding to the present experimental conditions matches the $\mathrm{Cu}_{2} \mathrm{O}$ reference spectrum. $\mathrm{Cu}, \mathrm{Cu}_{2} \mathrm{O}$ and $\mathrm{CuO}$ reference spectra are taken from [15]. 

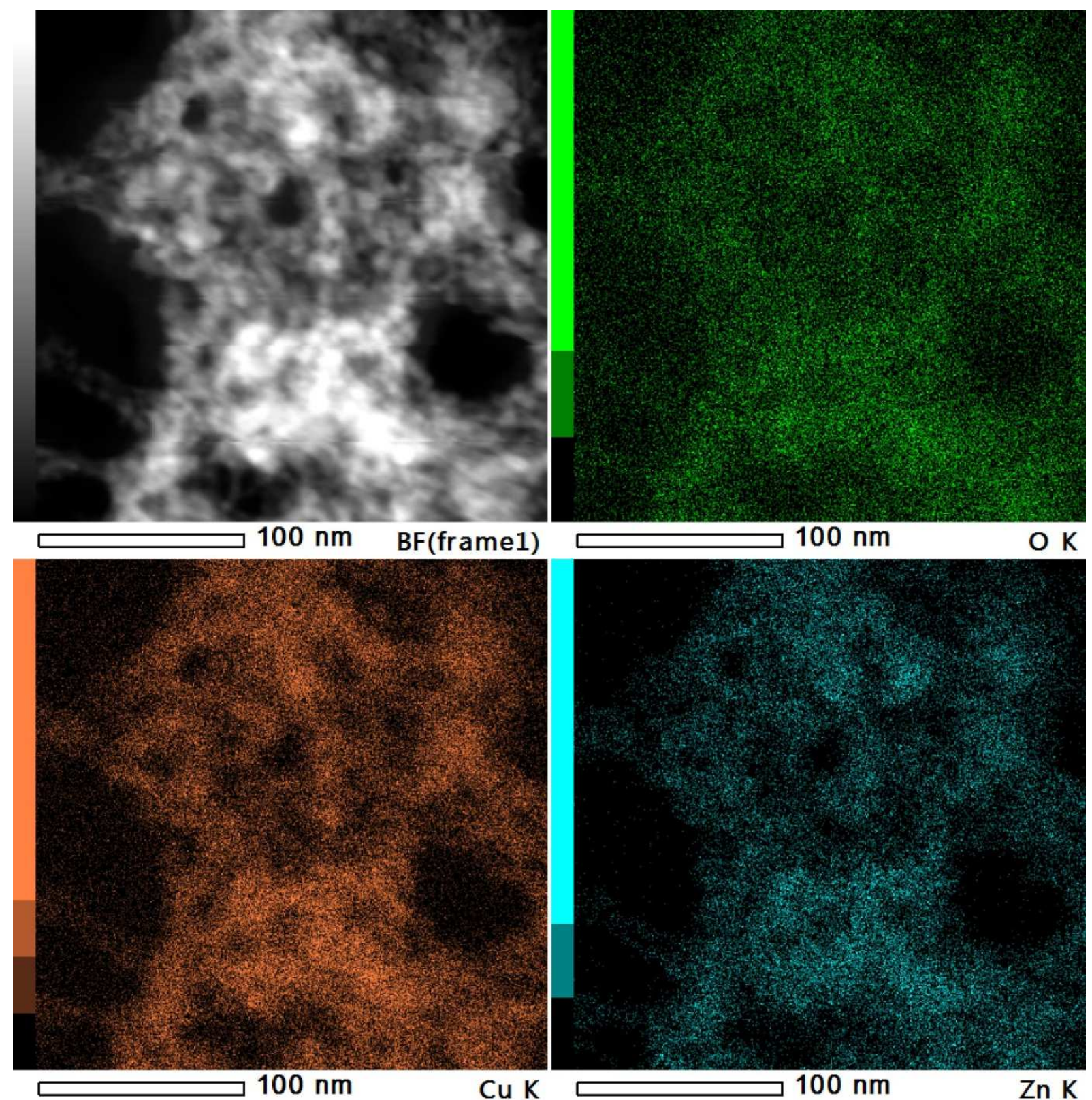

Figure 4: $\mathrm{X}$-mapping of a large aggregate of NPs showing that $\mathrm{Cu}_{2} \mathrm{O}$ and $\mathrm{ZnO}$ NPs are homogeneously distributed in this aggregate. 


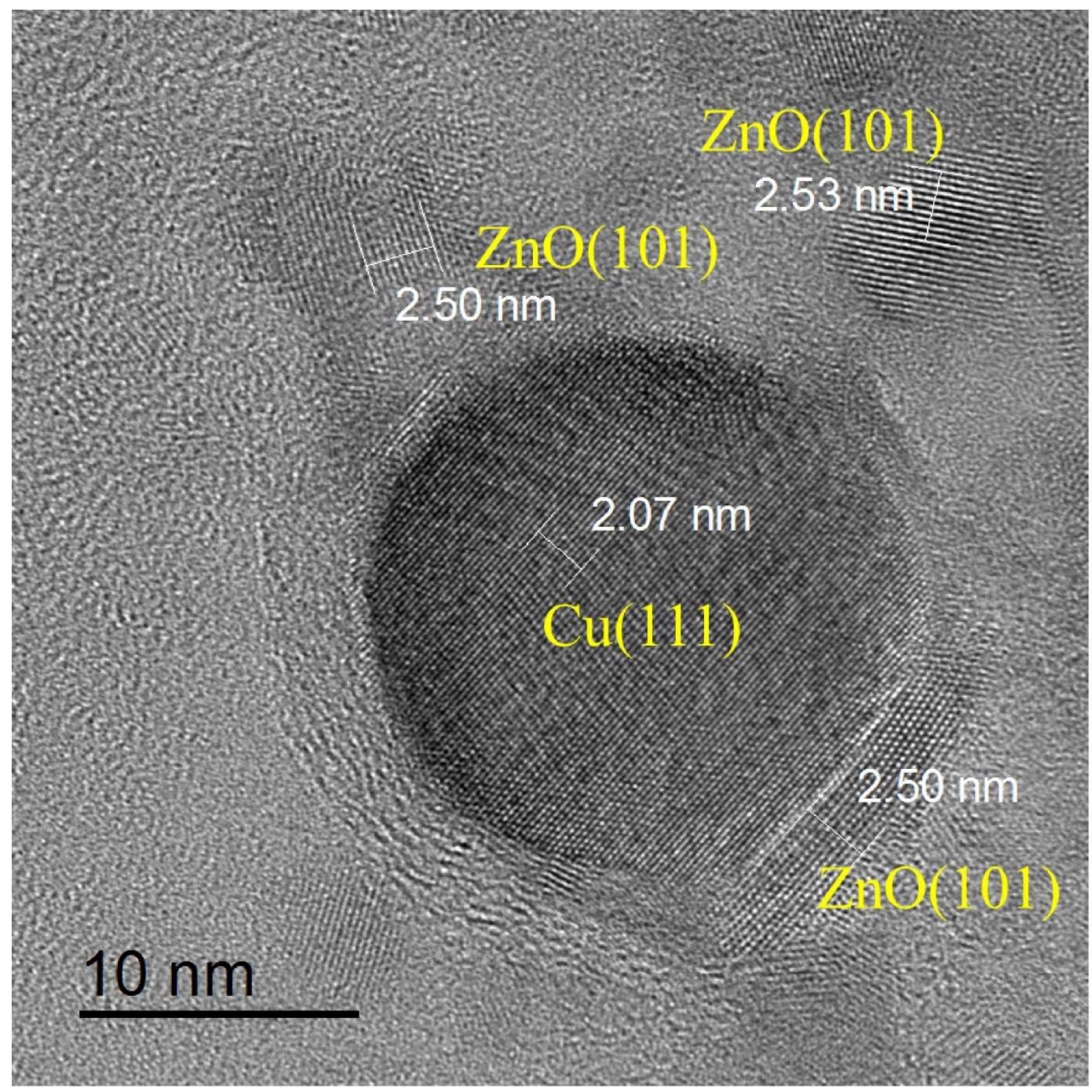

Figure 5: High-resolution image showing a $\mathrm{Cu} @ \mathrm{ZnO}$ core-shell structure of a small-size ( $18 \mathrm{~nm}$ in diameter) nanoparticle. 

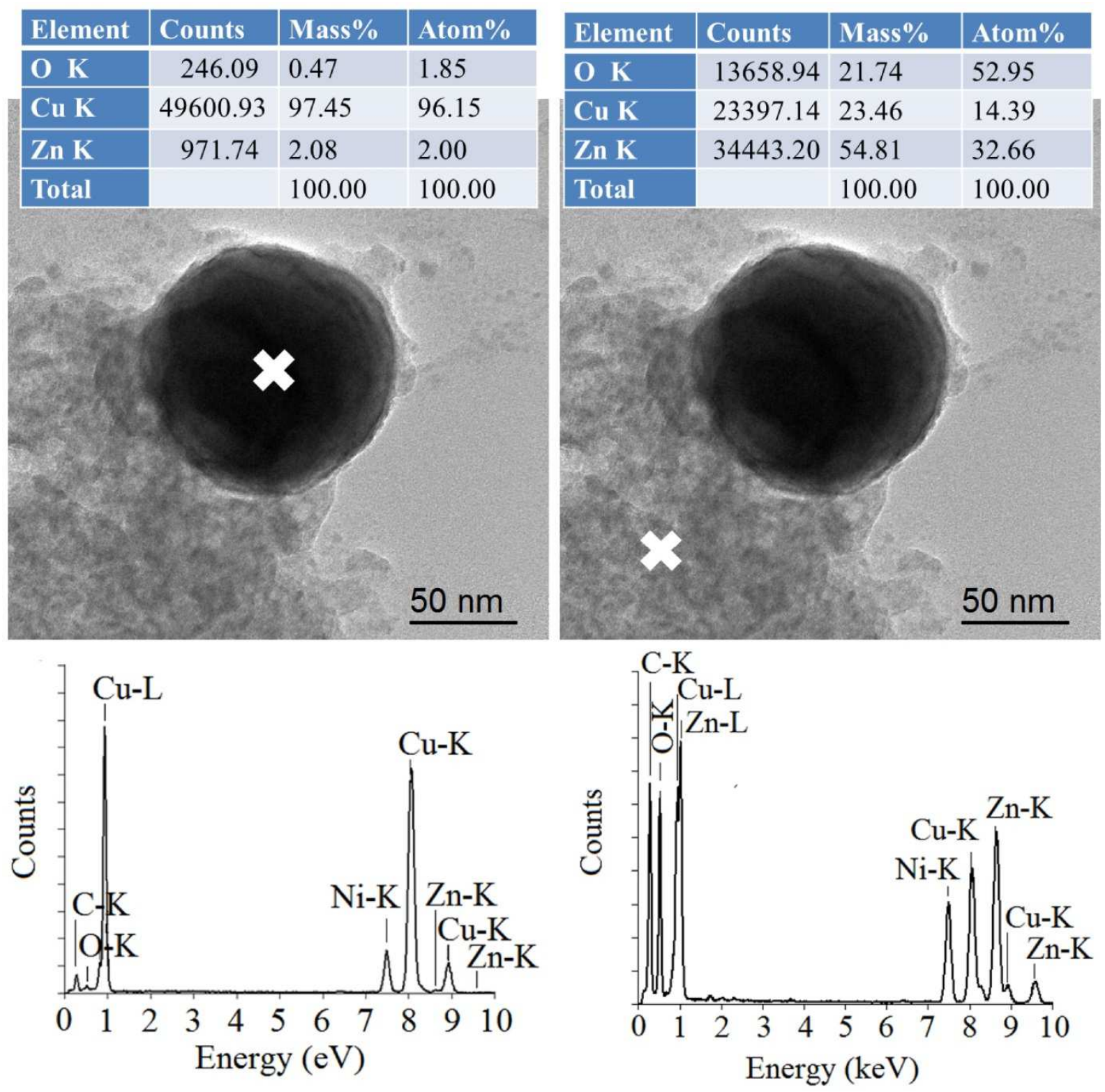

Figure 6: EDX spectra recorded at the cross and corresponding elemental analyses of a medium-size ( 115 nm in diameter) $\mathrm{Cu} @$ ZnO core-shell NPs. Nickel is due to the TEM grid. 

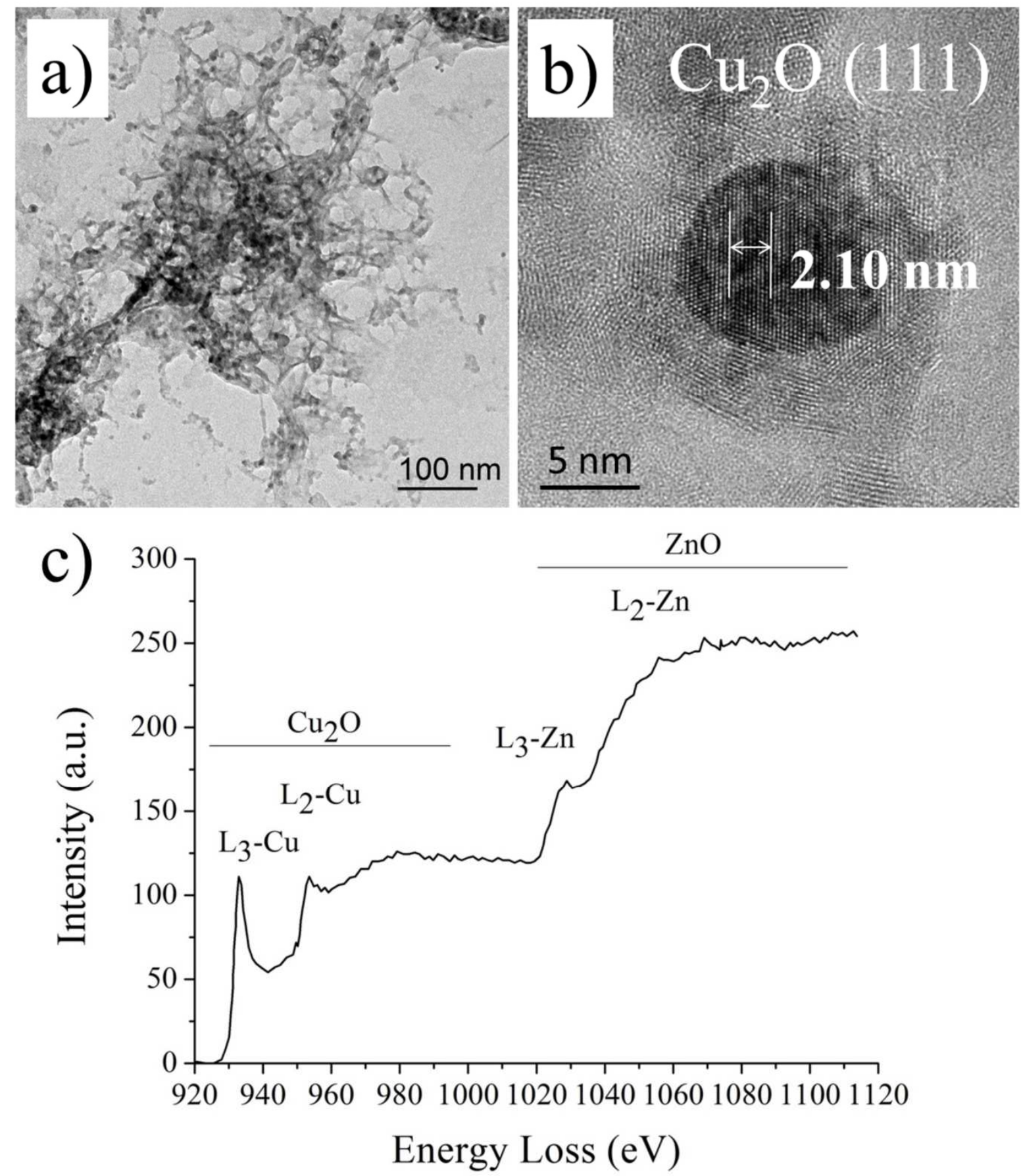

Figure 7: a) Low magnification bright field TEM images of NPs synthesized with one zinc electrode and one copper electrode mounted opposite one another. The sheet-like structure of agglomerates is clear. b) High resolution TEM images showing crystalline $\mathrm{Cu}_{2} \mathrm{O} @ \mathrm{ZnO}$ NPs. The interplanar distance is measured from 10 consecutive planes, as depicted by arrows. c) Electron Energy Loss spectrum corresponding to the $\mathrm{Cu}-\mathrm{L}$ and $\mathrm{Zn}-\mathrm{L}$ edges showing the presence of $\mathrm{Cu}_{2} \mathrm{O}$ and $\mathrm{ZnO}$. 


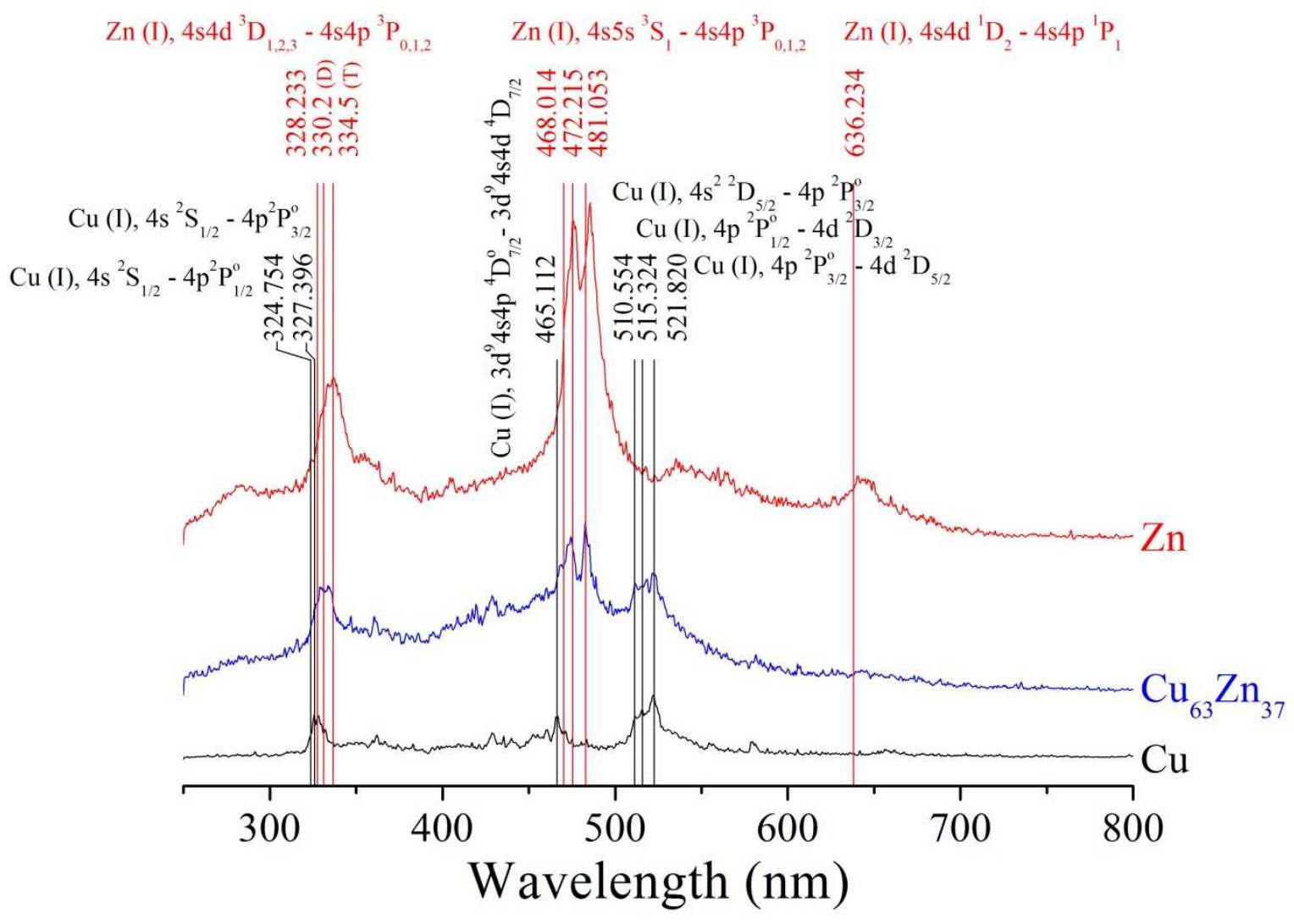

Figure 8: Main transitions observed during discharges in liquid nitrogen when both electrodes are made of zinc, copper or brass. 

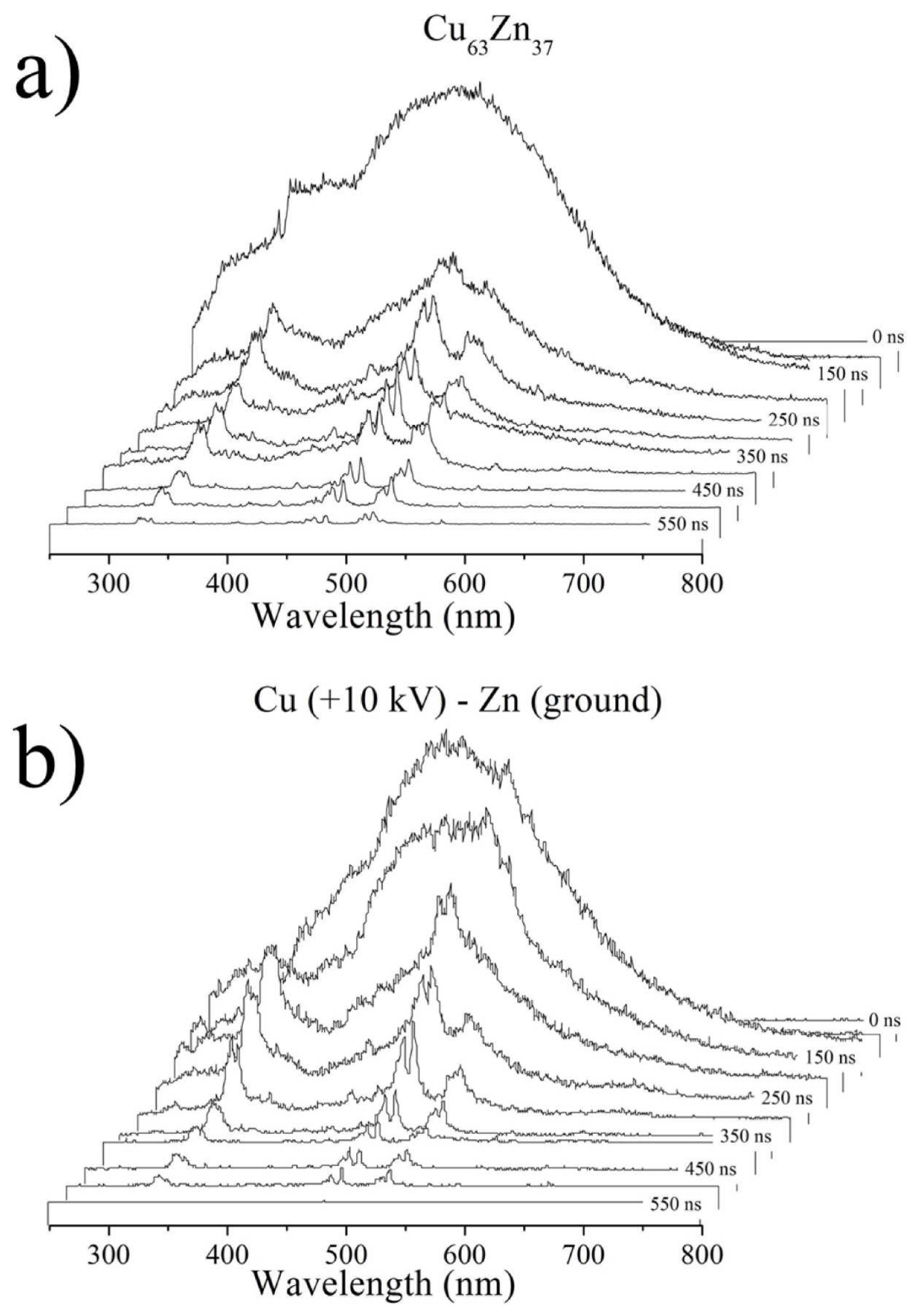

Figure 9: Time evolution of optical emission spectra recorded every $50 \mathrm{~ns}$ when both electrodes are made of brass a) and when high voltage is applied to the copper electrode, the zinc electrode being grounded. 


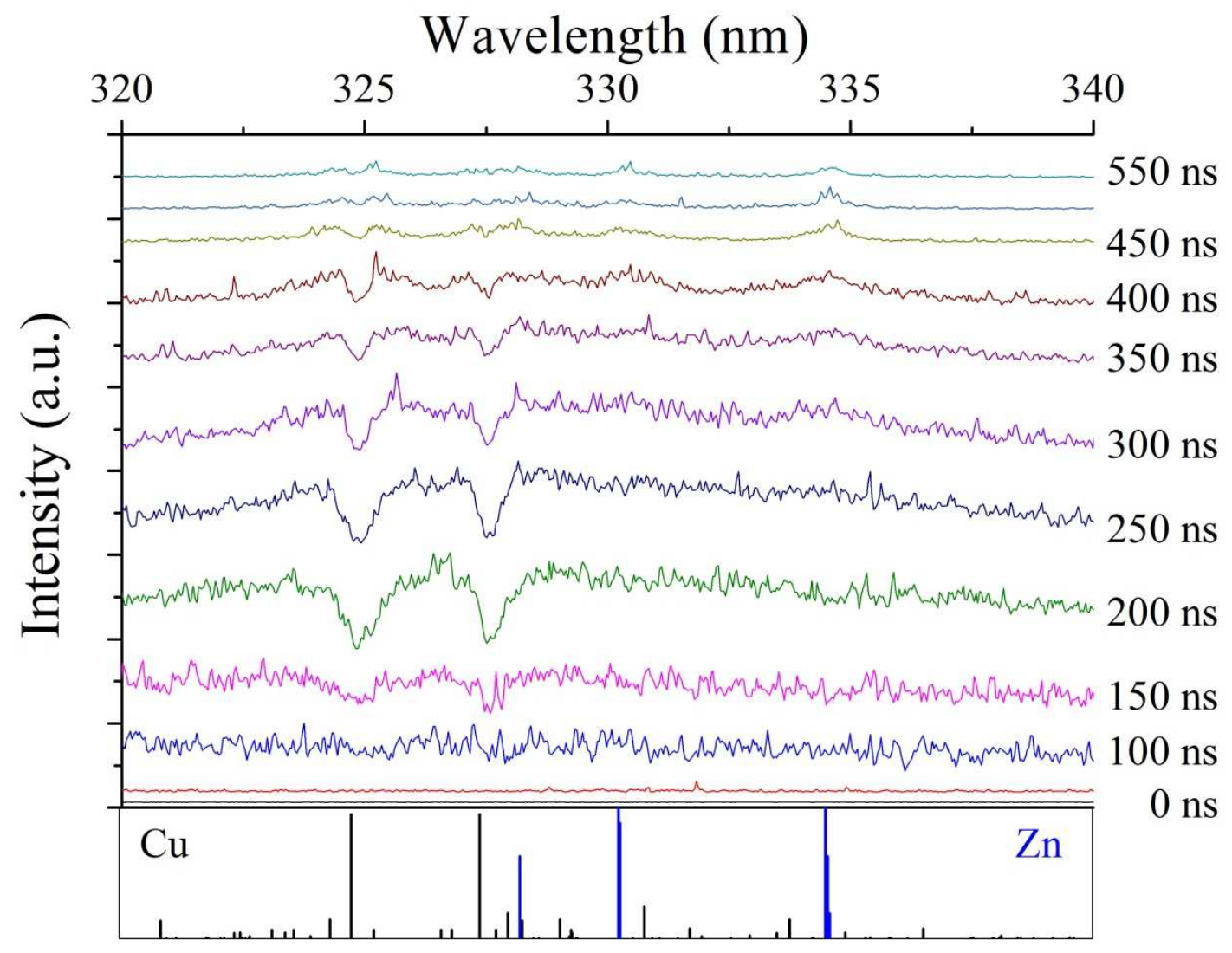

Figure 10: Self-absorption of $\mathrm{Cu}$ resonant lines observed in the case of brass electrodes with a $1,200 \mathrm{~g} \mathrm{~mm}^{-1}$ grating. Copper (resp. zinc) lines referenced in NIST [16] are shown by vertical black (resp. blue) threads whose length is proportional to the relative intensity of the line. Data at 0,50 and $100 \mathrm{ns,}$, where no self-absorption is noticed, are not reported to better depict the time evolution of self-absorbed lines. 

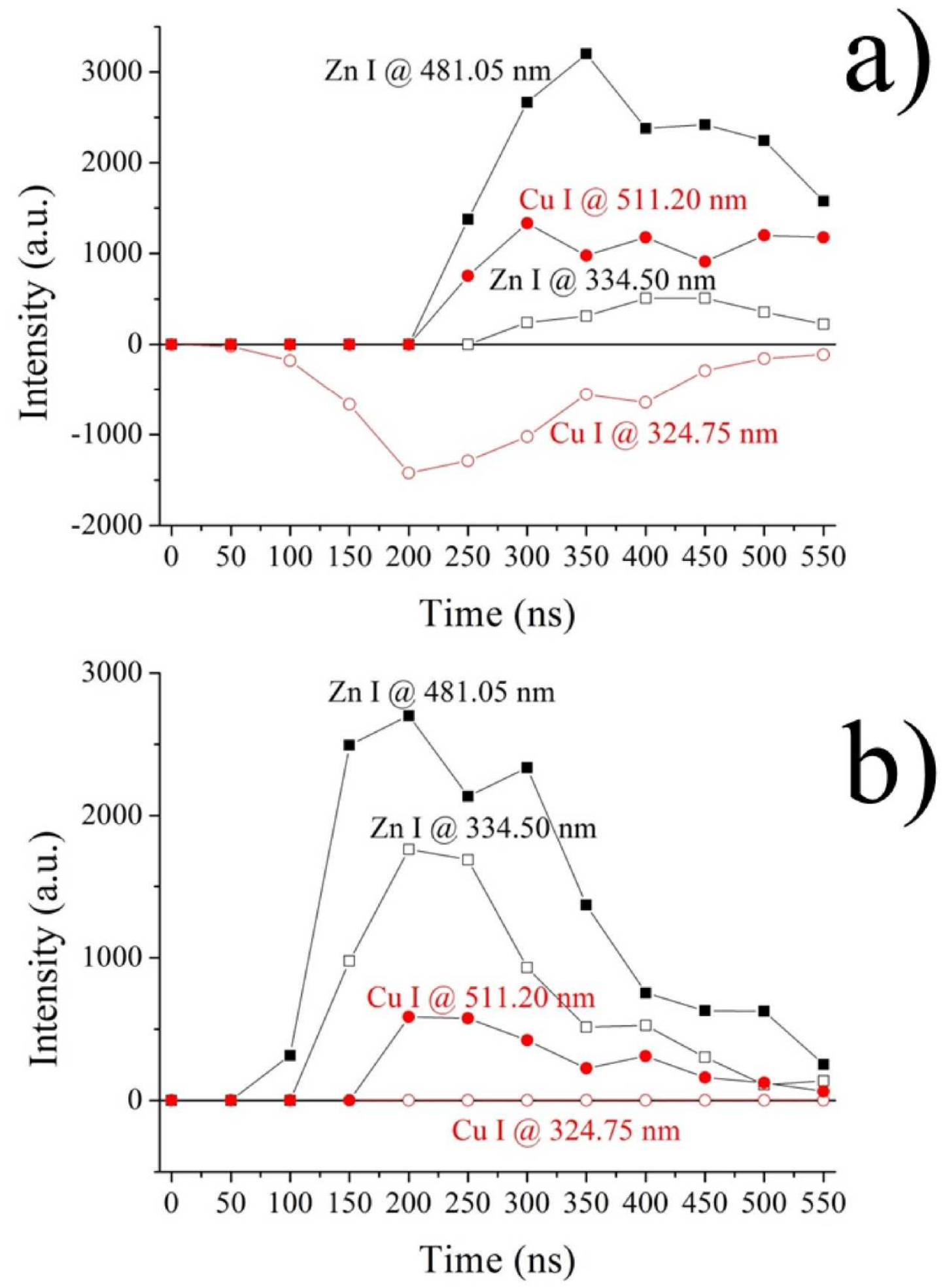

Figure 11: Time evolution of selected lines a) when both electrodes are made of brass a) and when high voltage is applied to the copper electrode, the other zinc electrode being grounded. 


\begin{tabular}{|l|l|l|}
\hline & Weight\% & Atom $\%$ \\
\hline O & 3.29 & 11.90 \\
\hline $\mathrm{Cu}$ & 92.20 & 84.10 \\
\hline $\mathrm{Zn}$ & 4.51 & 4.00 \\
\hline
\end{tabular}

\begin{tabular}{|l|l|l|}
\hline & Weight $\%$ & Atom $\%$ \\
\hline C & 13.03 & 37.60 \\
\hline O & 9.34 & 20.24 \\
\hline Cu & 65.51 & 35.74 \\
\hline Zn & 12.12 & 6.43 \\
\hline
\end{tabular}
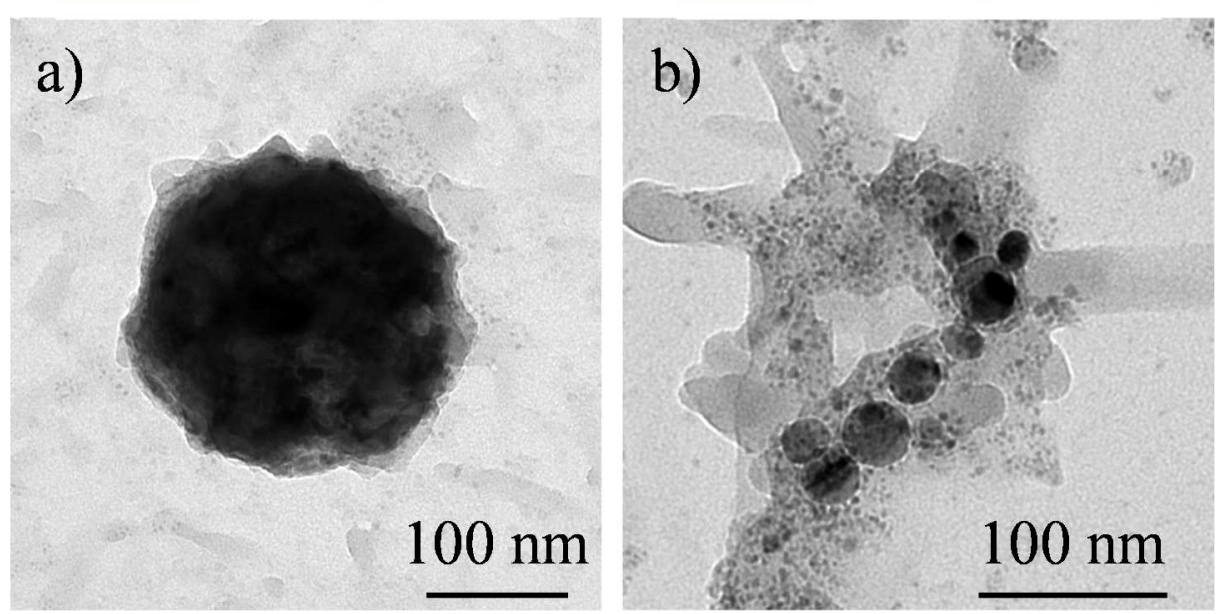

Figure 12: Nanoparticles synthesized from $\mathrm{Cu}_{63} \mathrm{Zn}_{37}$ electrodes in a) water and b) ethanol. Composition of large particles is provided on top. 
SUPPLEMENTAL MATERIAL 1
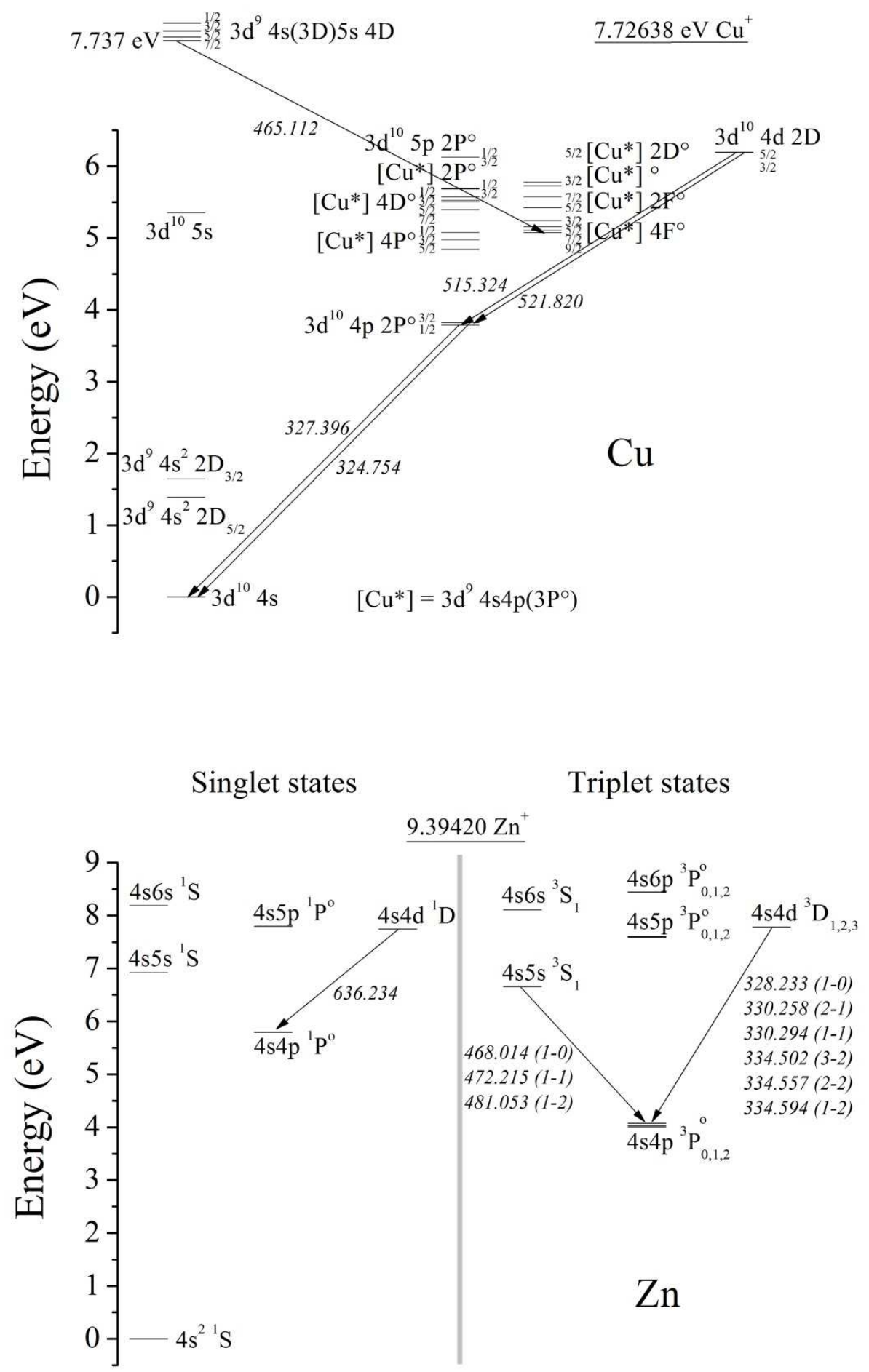

Supplemental Material 1: Grotrian diagrams of $\mathrm{Cu}$ and $\mathrm{Zn}$ displaying some transitions that are observed experimentally. 

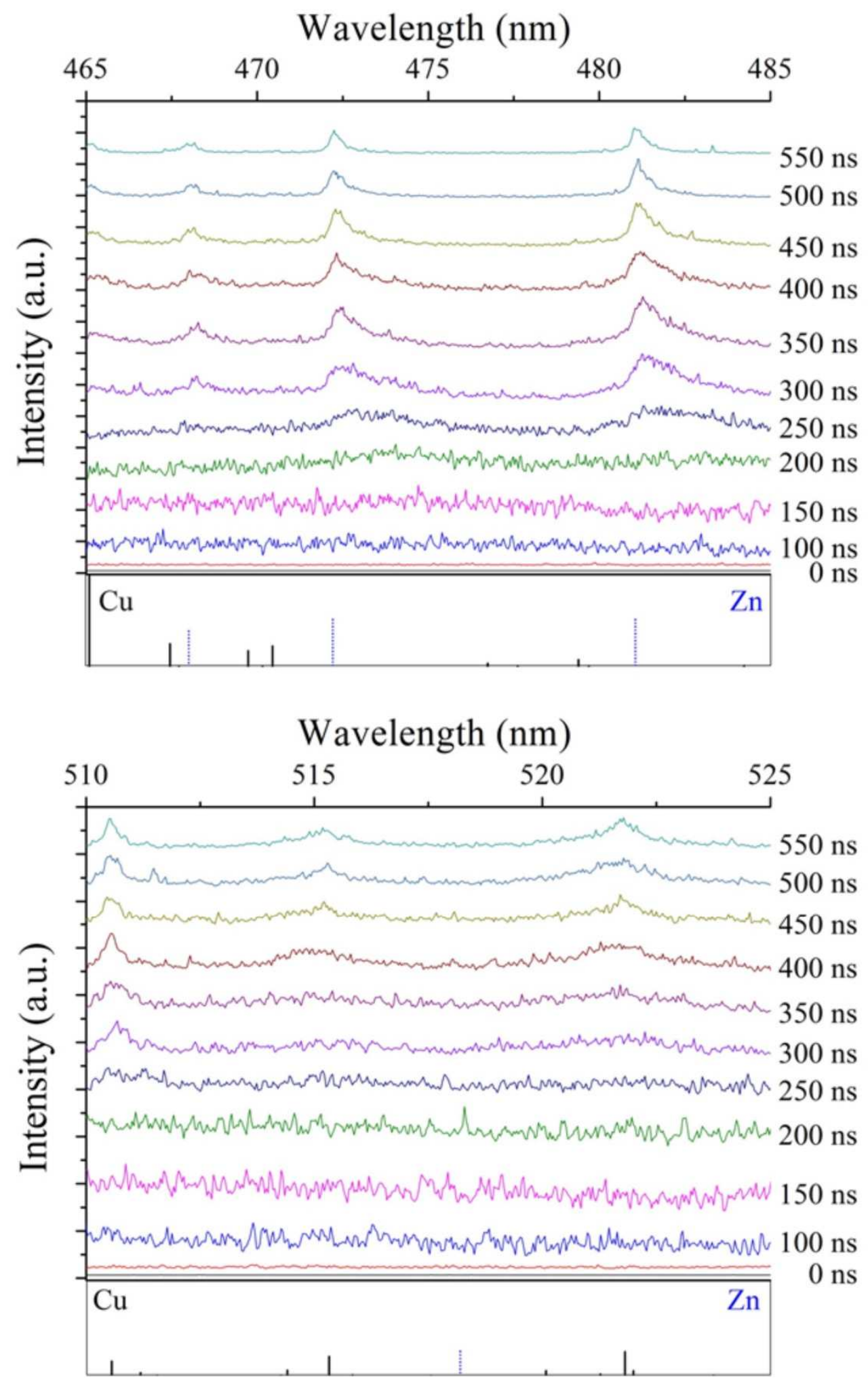

Supplemental Material 2: Time-resolved optical emission spectra recorded for selected wavelength ranges. $+10 \mathrm{kV}$ discharges between two $\mathrm{Cu}_{63} \mathrm{Zn}_{37}$ electrodes. Spectra were recorded with a 1200 grooves $\mathrm{mm}^{-1}$ grating. 
SUPPLEMENTAL MATERIAL 3

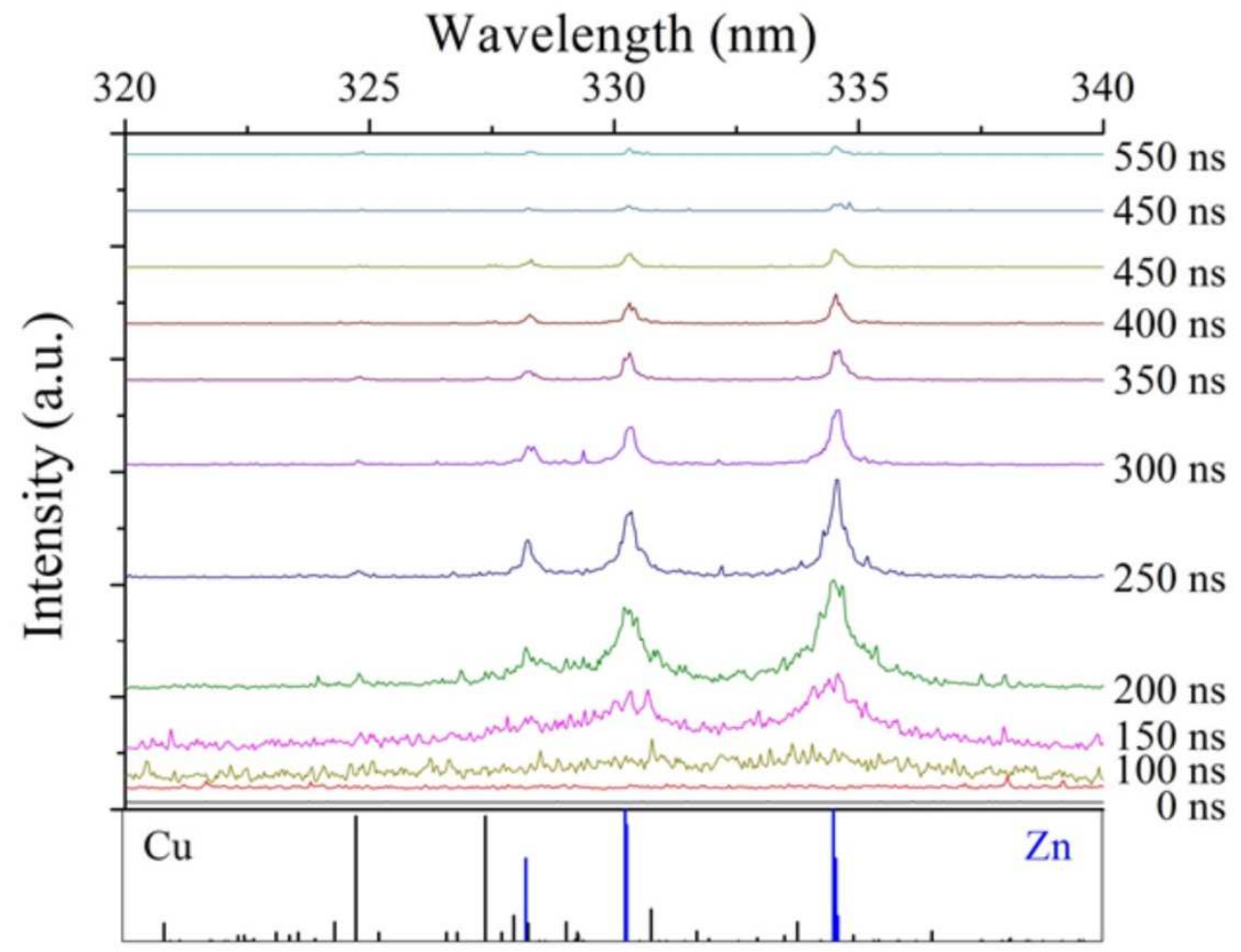

Wavelength (nm)

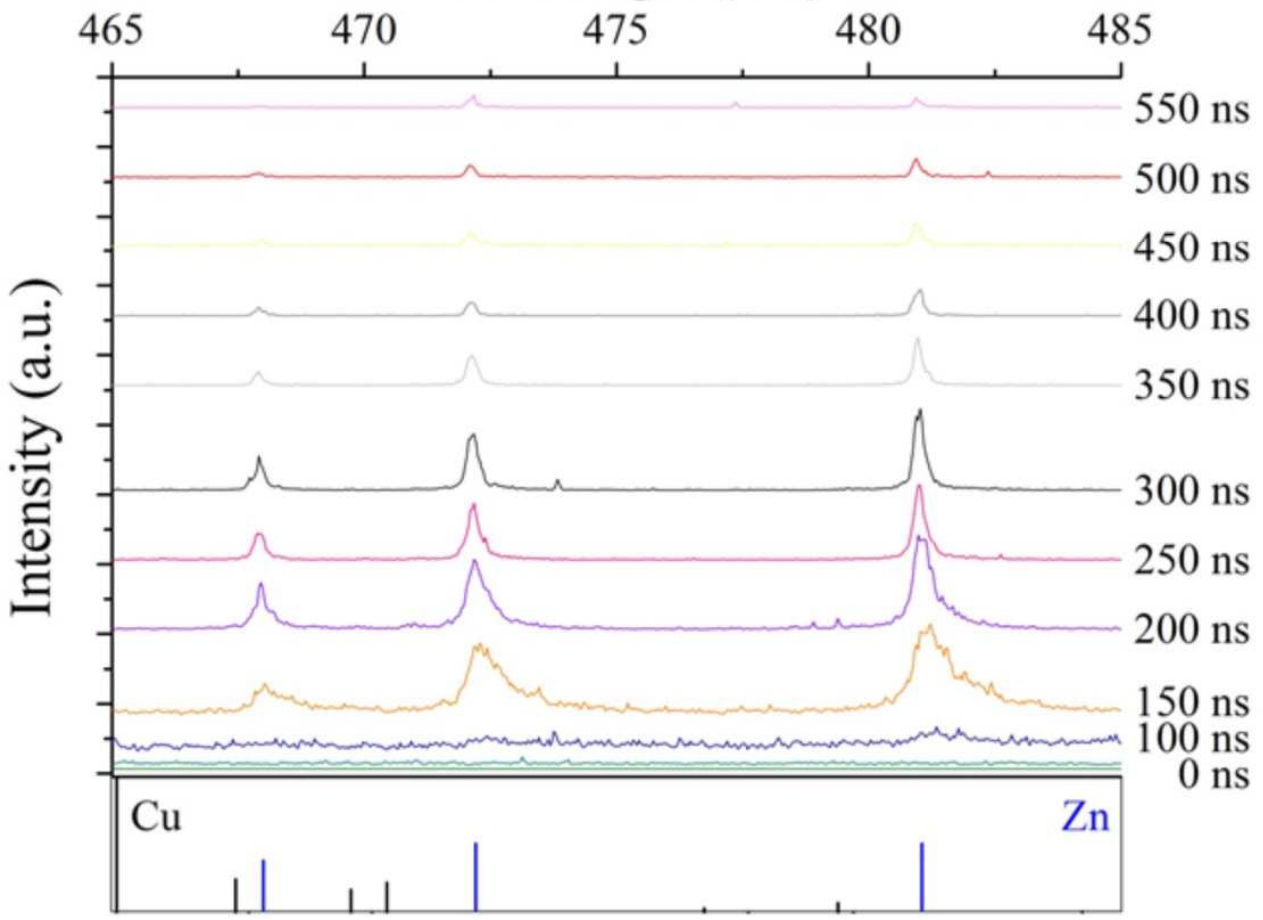

Supplemental Material 3: Time-resolved optical emission spectra recorded for selected wavelength ranges. $+10 \mathrm{kV}$ discharges between one $\mathrm{Cu}$ electrode $(\mathrm{HV})$ and one zinc electrode (grounded). Spectra were recorded with a 1200 grooves $\mathrm{mm}^{-1}$ grating. 